\title{
IDENTIFIKASI FAKTOR PENYEBAB COST OVERRUN (PEMBENGKAKAN BIAYA) PADA PROYEK RUMAH TINGGAL
}

\author{
Jason Christopher ${ }^{1}$ dan Mega Waty ${ }^{2}$ \\ ${ }^{1}$ Program Studi Sarjana Teknik Sipil, Universitas Tarumanagara, Jl. Letjen S. Parman No.1 Jakarta \\ jason.325170050@stu.untar.ac.id \\ ${ }^{2}$ Program Studi Sarjana Teknik Sipil, Universitas Tarumanagara, Jl. Letjen S. Parman No.1 Jakarta \\ mega@ft.untar.ac.id
}

\begin{abstract}
The advancement of the construction sector has made the complexity of a project increase in line with the increasing demands on construction engineers to complete a project on time, in accordance with cost, and prioritize quality. From that statement, a cost overrun problem shows in the process of running the project. Several techniques have been espoused by innovative organizational and managerial practices to reduce the risk of cost overrun from the construction project, but cost overrun in project construction remain as a one of the problem. This study aims to identify the factors that cause cost overrun in residential projects. The process of data collection was carried out using a questionnaire as the instrument. The data from the questionnaire is primary data that will be processed with the help of IBM SPSS 25 software. The identification of the factors causing the cost overrun using the relative important index (RII) method to determine the level of importance of each variable. The results of this study indicate that the project data and information are incomplete (when aanwijzing) and the erroneous estimation of material costs and wages are the main factors causing cost overrun with an RII value $\geq 0,9$.
\end{abstract}

Keywords: cost overrun; relative importance index; IBM SPSS 25

\begin{abstract}
ABSTRAK
Majunya sektor pekerjaan konstruksi membuat kompleksitas suatu proyek semakin meningkat sejalan dengan meningkatnya tuntutan kepada pelaku konstruksi untuk menyelesaikan proyek secara tepat waktu, sesuai dengan biaya, dan mengendepankan kualitas. Dari tuntutan tersebut, timbul suatu masalah cost overrun (pembengkakan biaya) dalam proses berjalannya proyek. Berbagai upaya telah dilakukan oleh berbagai organisasi mandiri dan praktisi manajemen untuk mengurangi risiko dari adanya cost overrun (pembengkakan biaya) pada suatu proyek, namun masalah cost overrun tetap menjadi salah satu problema dalam proyek konstruksi. Penelitian ini bertujuan untuk mengidentifikasi faktor-faktor penyebab terjadinya cost overrun (pembengkakan biaya) pada proyek rumah tinggal. Proses pengumpulan data dilakukan dengan menggunakan kuesioner sebagai instrumennya. Data dari kuesioner tersebut merupakan data primer yang akan diolah dengan bantuan software IBM SPSS 25. Pengidentifikasian faktor-faktor penyebab terjadinya cost overrun menggunakan metode relative importance index (RII) untuk menentukan tingkat kepentingan setiap variabel. Hasil dari penelitian ini menunjukaan bahwa data dan informasi proyek kurang lengkap (saat aanwijzing) dan perencanaan estimasi biaya material dan upah yang keliru menjadi faktor paling utama penyebab cost overrun dengan nilai $\mathrm{RII} \geq 0,9$.
\end{abstract}

Kata kunci: pembengkakan biaya; relative importance index; IBM SPSS 25

\section{PENDAHULUAN}

Eksistensi dari industri kontruksi secara tidak langsung berdampak pada berkembangnya proyek perumahan. Hal ini didukung dengan perkembangan pemukiman yang meningkat seiring dengan berjalannya waktu berdasarkan minat dan daya beli masyarakat untuk memenuhi kebutuhannya akan hunian yang nyaman dan asri (Tolangi, Rantung, Langi, \& Sibi, 2012)

Kemampuan untuk membuat estimasi biaya yang akurat penting demi suksesnya pekerjaan konstruksi. Berbagai upaya telah dilakukan oleh berbagai organisasi mandiri dan praktisi manajemen untuk mengurangi risiko dari adanya cost overrun pada suatu proyek, namun masalah cost overrun tetap menjadi salah satu problema dalam proyek konstruksi (Love, Wang, Sing, \& Tiong, 2013). 
Berdasarkan pemaparan latar belakang diatas, rumusan masalah pada penelitian ini adalah faktor-faktor apa saja yang teridentifikasi menjadi penyebab terjadinya cost overrun pada proyek rumah tinggal 2 (dua) lantai di Jakarta? Penelitian ini bertujuan untuk mengetahui identifikasi faktor-faktor penyebab terjadinya cost overrun pada proyek rumah tinggal 2 (dua) lantai di Jakarta.

\section{Cost Overrun}

Cost overrun dapat dikatakan sebagai suatu besaran dimana biaya aktual melebihi estimasi biaya yang direncanakan dengan biaya yang diukur dalam mata uang dan kestabilan harga. Frekuensi, ukuran, dan distribusi dari cost overrun harus diperhitungkan sebagai bagian dari penilaian cost overrun untuk jenis investasi tertentu. (Flyvbjerg, et al., 2018).

\section{Estimasi Biaya}

Keakuratan dari perencaaan biaya ini akan meningkat sejalan dengan perkembangan berjalannya proyek tersebut. Aspek-aspek yang dianggap menjadi beban pada proyek akan dimasukkan kedalam estimasi biaya tersebut. Aspek tersebut diantaranya: tenaga kerja, bahan, peralatan, fasilitas, dan layanan. Dari semua aspek tersebut, dapat dikatakan bahwa estimasi biaya merupakan penilaian secara kuantitatif dari semua probabilitas yang diperlukan untuk menyelesaikan proyek dengan penyajian ringkas (PMBOK Guide, 2013).

Estimasi biaya proyek yang direncanakan tidak dapat dilakukan tanpa pikir panjang dengan persepsi optimis atau pesimis terhadap prediksi suatu pekerjaan. Dalam mendefinisikan estimasi biaya proyek, perlu diingat bahwa estimasi tersebut didasarkan pada beberapa faktor, diantaranya: penentuan proyek, administrasi kontrak, penjadwalan proyek, peralatan konstruksi, produktivitas sumber daya manusia, dan metode estimasi. Perencanaan estimasi biaya juga tidak lepas dari adanya pengendalian biaya proyek demi mengoptimalkan penggunaan biaya proyek (Ritz, 1994).

\section{Pengendalian Biaya Proyek}

Pengendalian biaya proyek diperlukan pada proyek konstruksi sebagai jaminan bahwa penggunaan biaya telah sesuai dengan anggaran yang telah dibuat. Jika dalam pelaksanaanya terdapat adanya perubahan pekerjaan, maka akan dilakukan peninjauan ulang mengenai anggaran biaya dengan persetujuan dari pihak yang terlibat. Pada pelaksanaanya, suatu proyek memerlukan input atau masukan untuk mengukur dan menilai realisasi biaya selama proyek berlangsung. Input atau masukan tersebut diantaranya (Departemen Pekerjaan Umum, 2007):

1. Perencanaan manajemen proyek.

2. Persetujuan terhadap adanya perubahan pekerjaan

3. Informasi kinerja pekerjaan

4. Informasi mengenai progress atau perkembangan proyek.

5. Cost baseline

6. Project funding requirements

\section{METODE PENELITIAN}

Prosedur penelitian ini dijabarkan sebagai berikut:

1. Berdasarkan dari judul yang sudah ditentukan, dilakukan studi terhadap manajemen biaya, cost overrun, dan rumah tinggal dari jurnal dan literatur yang ada.

2. Setelah dilakukan studi dari jurnal dan literatur, dilakukan pengumpulan data dari penyebaran kuesioner kepada direktur, project manager, site engineer, site manager, dan konsultan perencana sebagai bentuk data primer penelitian ini.

3. Data yang sudah terkumpul kemudian diolah dan dilakukan analisis dengan pengujian validitas, reliabilitas, dan Relative Importance Index sebagai bentuk pembahasan dari penelitian.

4. $\quad$ Proses terakhir dari penelitian ini adalah menyimpulkan pembahasan dan membuat saran dari studi yang sudah dilakukan.

\section{Diagram Alir Penelitian}

Prosedur penelitian yang telah dijabarkan diatas, akan digambarkan di diagram alir pada Gambar 1. di bawah ini. 


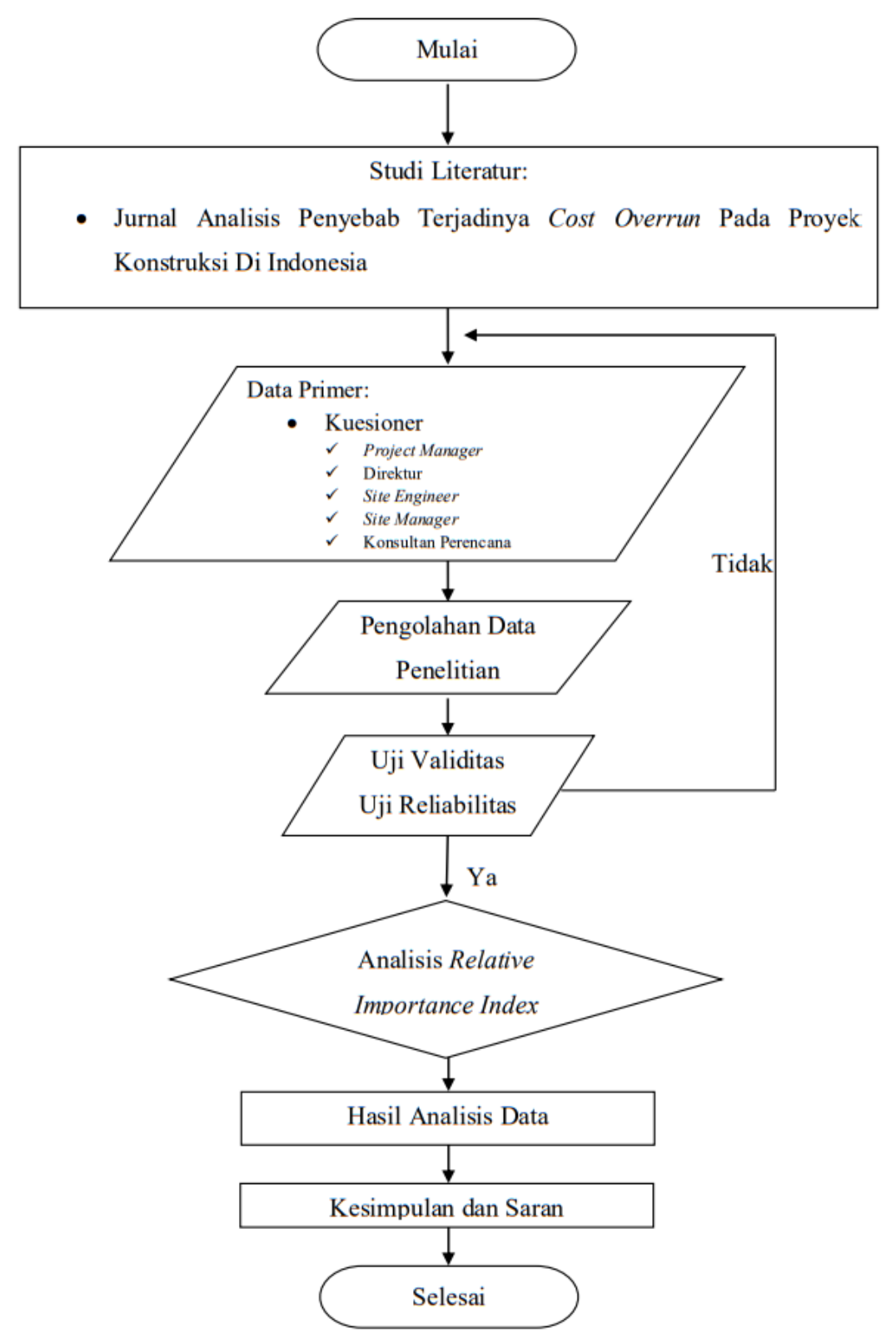

Gambar 1. Diagram Alir Penelitian

\section{Lokasi Penelitian}

Lokasi penelitian yang ditargetkan untuk penelitian adalah daerah Jakarta dengan objek yang dituju adalah proyek rumah tinggal 2 (dua) lantai. Pemilihan Kota Jakarta sebagai target penelitian dikarenakan tiap tahunnya proyek rumah tinggal menjadi salah satu proyek yang cukup banyak tersedia sekaligus sebagai ibu kota negara.

\section{Jenis Data}

Penelitian yang disusun oleh peneliti menggunakan data primer sebagai bahan untuk mengkaji masalah yang dibahas. Pada penelitian tentang cost overrun pada proyek rumah tinggal 2 (dua) lantai di Jakarta ini, peneliti menggunakan data primer dengan target yang dituju adalah direktur kontraktor, project manager, site engineer, site manager, dan konsultan perencana yang mengerjakan proyek tersebut

\section{Pengumpulan Data}

Pengumpulan data dilakukan dengan penyebaran kuesioner kepada penyedia jasa konstruksi yang telah terdaftar dalam anggota GAPENSI (Gabungan Pelaksana Konstruksi Nasional Indonesia) zona DKI Jakarta. Pendataan dilakukan di 5 wilayah Kota Jakarta dengan pelaksana konstruksi yang didata adalah pelaksana konstruksi yang berkecimpung dalam proyek rumah tinggal dengan kualifikasi perusahaan besar dan menengah. 


\section{Perancangan Kuesioner}

Berikut ini akan dijabarkan mengenai kuesioner yang disebar kepada responden, terdapat pada Tabel 1. dibawah ini.

Tabel 1. Draf Kuesioner

\begin{tabular}{|c|c|c|c|}
\hline No & Faktor & Variabel & Simbol \\
\hline \multirow{4}{*}{1} & \multirow{4}{*}{ Estimasi Biaya } & $\begin{array}{l}\text { Data dan Informasi Proyek Kurang Lengkap (Saat } \\
\text { Aanwijzing) }\end{array}$ & $\mathrm{X} 1.1$ \\
\hline & & $\begin{array}{l}\text { Perencanaan Estimasi Biaya Material dan Upah Yang } \\
\text { Keliru }\end{array}$ & $\mathrm{X} 1.2$ \\
\hline & & $\begin{array}{l}\text { Kekeliruan dan Kesalahan Dalam Pengontrolan Biaya } \\
\text { Proyek }\end{array}$ & $\mathrm{X} 1.3$ \\
\hline & & Tidak Memperhitungkan Biaya Tak Terduga & $\mathrm{X} 1.4$ \\
\hline \multirow{4}{*}{2} & \multirow{4}{*}{$\begin{array}{l}\text { Pelaksanaan dan } \\
\text { Hubungan Kerja }\end{array}$} & $\begin{array}{l}\text { Sering Terjadinya Perubahan Gambar Atau Desain } \\
\text { Pada Pelaksanaan Pekerjaan Lapangan Oleh Owner }\end{array}$ & $\mathrm{X} 2.1$ \\
\hline & & $\begin{array}{l}\text { Koordinasi Yang Kurang Baik Antara Site Manager dan } \\
\text { Pekerja Proyek Di Lapangan }\end{array}$ & $\mathrm{X} 2.2$ \\
\hline & & Tidak Cakapnya Pengawasan Proyek Di Lapangan & $\mathrm{X} 2.3$ \\
\hline & & $\begin{array}{l}\text { Banyak Hasil Pekerjaan Yang Harus Diulangi Atau } \\
\text { Diperbaiki Karena Cacat Atau Salah }\end{array}$ & $\mathrm{X} 2.4$ \\
\hline \multirow{3}{*}{3} & \multirow{3}{*}{ Sumber Daya Manusia } & $\begin{array}{l}\text { Buruknya Etos Kerja Dari Para Pekerja Yang } \\
\text { Menyebabkan Terjadinya Kelalaian Pada Pekerjaan } \\
\text { Proyek }\end{array}$ & X3.1 \\
\hline & & $\begin{array}{l}\text { Produktivitas dan Kualitas Sumber Daya Manusia Yang } \\
\text { Buruk }\end{array}$ & X3.2 \\
\hline & & Besarnya Upah atau Gaji Sumber Daya Manusia & X3.3 \\
\hline \multirow{6}{*}{4} & \multirow{6}{*}{ Material } & $\begin{array}{l}\text { Tidak Memperhitungkan Inflasi Ekonomi Nasional dan } \\
\text { Eskalasi Kenaikan Harga Material }\end{array}$ & $\mathrm{X} 4.1$ \\
\hline & & $\begin{array}{l}\text { Terjadinya Manipulasi Pada Logistik Proyek (Bekerja } \\
\text { Sama Dengan Supplier Material) Sehingga Jumlah } \\
\text { Pengiriman Material Berlebihan Atau Kekurangan }\end{array}$ & $\mathrm{X} 4.2$ \\
\hline & & $\begin{array}{l}\text { Kontrol dan Pengendalian Kualitas Material Yang } \\
\text { Buruk }\end{array}$ & $\mathrm{X} 4.3$ \\
\hline & & $\begin{array}{l}\text { Terlambat Atau Kurangnya Pasokan Material Pada Saat } \\
\text { Pelaksanaan }\end{array}$ & $\mathrm{X} 4.4$ \\
\hline & & $\begin{array}{l}\text { Pengawasan Logistik Yang Lemah Sehingga Terjadi } \\
\text { Hilangnya Bahan Material }\end{array}$ & $\mathrm{X} 4.5$ \\
\hline & & Tidak Adanya Penjadwalan Dalam Pengadaan Material & $\mathrm{X} 4.6$ \\
\hline \multirow{3}{*}{5} & \multirow{3}{*}{ Peralatan } & $\begin{array}{l}\text { Harga Sewa Atau Beli Peralatan Yang Tinggi Akibat } \\
\text { Tidak Dilakukan Survei Terlebih Dahulu }\end{array}$ & X5.1 \\
\hline & & $\begin{array}{l}\text { Biaya Mobilisasi Atau Demobilisasi Peralatan Yang } \\
\text { Tinggi Akibat Tidak Cermat Dalam Pengamatan di } \\
\text { Lokasi Proyek }\end{array}$ & $\mathrm{X} 5.2$ \\
\hline & & $\begin{array}{l}\text { Adanya Kerusakan Terhadap Peralatan } \text { Yang } \\
\text { Digunakan }\end{array}$ & X5.3 \\
\hline
\end{tabular}


(lanjutan) Tabel 1. Draf Kuesioner

\begin{tabular}{|c|c|c|c|}
\hline No & Faktor & Variabel & Simbol \\
\hline \multirow{4}{*}{6} & \multirow{4}{*}{ Waktu Pelaksanaan } & Sering Terjadi Penundaan Pekerjaan & X6.1 \\
\hline & & $\begin{array}{l}\text { Instruksi Gambar dan pelaksanaan Tidak Dipahami } \\
\text { Oleh pekerja proyek Sehingga Terjadi Pekerjaan Yang } \\
\text { Salah Atau Keliru }\end{array}$ & X6.2 \\
\hline & & Penjadwalan Proyek Yang Tidak Tepat Sasaran & X6.3 \\
\hline & & Buruknya Kondisi Cuaca & X6.4 \\
\hline \multirow{3}{*}{7} & \multirow{3}{*}{$\begin{array}{l}\text { Aspek Keuangan dan } \\
\text { Dokumen Proyek }\end{array}$} & Terlambatnya Proses Pembayaran Dari Owner & $\mathrm{X} 7.1$ \\
\hline & & Dokumen Kontrak Yang Kurang Lengkap & $\mathrm{X} 7.2$ \\
\hline & & $\begin{array}{l}\text { Perencanaan Durasi Kontrak Jangka Pendek Yang } \\
\text { Terlalu Dipaksakan }\end{array}$ & X7.3 \\
\hline
\end{tabular}

\section{HASIL DAN PEMBAHASAN}

\section{Deskripsi Responden}

Dari kuesioner yang telah disebar, didapat sebanyak 35 responden yang bersedia untuk mengisi kuesioner. Hasil tersebut sudah memenuhi sampel minimal, yaitu 34 berdasarkan rumus slovin dengan populasi dari penelitian ini sebanyak 37.

\section{Uji Validitas}

Uji validitas digunakan untuk memeriksa valid atau tidaknya dari variabel yang diteliti. Metode pengujian ini dilakukan dengan cara membandingkan nilai $\mathrm{r}$ yang dihitung menggunakan software dengan nilai $\mathrm{r}$ dari tabel. Variabel dinyatakan valid apabila nilai $\mathrm{r}$ hasil penghitungan lebih besar atau sama dengan nilai $\mathrm{r}$ tabel. Besarnya nilai $r$ tersebut dihitung dengan tingkat signifikasi sebesar 0,05. Berdasarkan jumlah sampel yang didapat (35), diketahui bahwa nilai $r$ tabel sebesar 0,334. Berikut ini akan dilampirkan hasil uji validitas pada Tabel 2. Dibawah ini.

Tabel 2. Hasil Uji Validitas

\begin{tabular}{ccccc}
\hline No & Simbol Variabel & R Hitung & R Tabel & Keterangan \\
\hline 1 & X1.1 & 0,568 & 0,334 & Valid \\
2 & X1.2 & 0,691 & 0,334 & Valid \\
3 & X1.3 & 0,661 & 0,334 & Valid \\
4 & X1.4 & 0,792 & 0,334 & Valid \\
5 & X2.1 & 0,629 & 0,334 & Valid \\
6 & X2.2 & 0,789 & 0,334 & Valid \\
7 & X2.3 & 0,697 & 0,334 & Valid \\
8 & X2.4 & 0,757 & 0,334 & Valid \\
9 & X3.1 & 0,759 & 0,334 & Valid \\
10 & X3.2 & 0,782 & 0,334 & Valid \\
11 & X3.3 & 0,761 & 0,334 & Valid \\
12 & X4.1 & 0,649 & 0,334 & Valid \\
13 & X4.2 & 0,795 & 0,334 & Valid \\
14 & X4.3 & 0,869 & 0,334 & Valid \\
\hline
\end{tabular}


Identifikasi Faktor Penyebab Cost Overrun

(lanjutan) Tabel 2. Hasil Uji Validitas

\begin{tabular}{ccccc}
\hline No & Simbol Variabel & R Hitung & R Tabel & Keterangan \\
\hline 15 & X4.4 & 0,817 & 0,334 & Valid \\
16 & X4.5 & 0,750 & 0,334 & Valid \\
17 & X4.6 & 0,863 & 0,334 & Valid \\
18 & X5.1 & 0,870 & 0,334 & Valid \\
19 & X5.2 & 0,790 & 0,334 & Valid \\
20 & X5.3 & 0,833 & 0,334 & Valid \\
21 & X6.1 & 0,800 & 0,334 & Valid \\
22 & X6.2 & 0,824 & 0,334 & Valid \\
23 & X6.3 & 0,877 & 0,334 & Valid \\
24 & X6.4 & 0,737 & 0,334 & Valid \\
25 & X7.1 & 0,842 & 0,334 & Valid \\
26 & X7.2 & 0,906 & 0,334 & Valid \\
27 & X7.3 & 0,876 & 0,334 & Valid \\
\hline
\end{tabular}

\section{Uji Reliabilitas}

Uji reliabilitas dilakuan untuk menentukan apakah kuesioner yang digunakan dapat konsisten berdasarkan analisis dengan software IBM SPSS 25. Dengan kata lain, uji reliabilitas dapat menjadi sumber apakah kuesioner yang telah terkumpul reliabel atau tidak. Kuesioner akan dinyatakan reliabel apabila jawaban dari responden konsisten terhadap satu pertanyaaan ke pertanyaan lain. Nilai dari cronbach alpha akan memutuskan reliabel atau tidaknya kuesioner penelitian tersebut. Nilai Cronbach's Alpha harus > 0,6 agar memiliki tingkat reliabilitas yang dapat diakui. Berikut ini akan dilampirkan hasil uji reliabilitas pada Tabel 3. dibawah ini

Tabel 3. Hasil Uji Reliabilitas

\begin{tabular}{cccc}
\hline No & Kategori & Cronbach’s Alpha & N of items \\
\hline 1 & Estimasi Biaya & 0,602 & 4 \\
2 & Pelaksanaan dan Hubungan Kerja & 0,682 & 4 \\
3 & Sumber Daya Manusia & 0,617 & 3 \\
4 & Material & 0,875 & 6 \\
5 & Peralatan & 0,777 & 3 \\
6 & Waktu Pelaksanaan & 0,819 & 4 \\
7 & Aspek Keuangan dan Dokumen & 0,844 & 4 \\
\end{tabular}

\section{Uji Relative Importance Index (RII)}

Berikut ini akan disajikan rekapitulasi hasil uji relative importance index (RII) dari penelitian yang telah dilakukan. Hasil uji RII akan disajikan pada Tabel 4. dibawah ini. 
Tabel 4. Hasil Uji Relative Importance Index

\begin{tabular}{|c|c|c|c|}
\hline No & Variabel & RII & Tingkat Kepentingan \\
\hline 1 & Perencanaan Estimasi Biaya Material dan Upah Yang Keliru & 0,9142 & Sangat Tinggi \\
\hline 2 & Data dan Informasi Proyek Kurang Lengkap (Saat Aanwijzing) & 0,9000 & Sangat Tinggi \\
\hline 3 & Kekeliruan dan Kesalahan Dalam Pengontrolan Biaya Proyek & 0,8761 & Sangat Tinggi \\
\hline 4 & $\begin{array}{l}\text { Banyak Hasil Pekerjaan Yang Harus Diulangi Atau Diperbaiki } \\
\text { Karena Cacat Atau Salah }\end{array}$ & 0,8428 & Sangat Tinggi \\
\hline 5 & $\begin{array}{l}\text { Sering Terjadinya Perubahan Gambar Atau Desain Pada } \\
\text { Pelaksanaan Pekerjaan Lapangan Oleh Owner }\end{array}$ & 0,8333 & Sangat Tinggi \\
\hline 6 & $\begin{array}{l}\text { Buruknya Etos Kerja Dari Para Pekerja Yang Menyebabkan } \\
\text { Terjadinya Kelalaian Pada Pekerjaan Proyek }\end{array}$ & 0,8333 & Sangat Tinggi \\
\hline 7 & Produktivitas dan Kualitas Sumber Daya Manusia Yang Buruk & 0,8333 & Sangat Tinggi \\
\hline 8 & Tidak Memperhitungkan Biaya Tak Terduga & 0,8285 & Sangat Tinggi \\
\hline 9 & $\begin{array}{l}\text { Instruksi Gambar dan pelaksanaan Tidak Dipahami Oleh pekerja } \\
\text { proyek Sehingga Terjadi Pekerjaan Yang Salah Atau Keliru }\end{array}$ & 0,8238 & Sangat Tinggi \\
\hline 10 & Tidak Cakapnya Pengawasan Proyek Di Lapangan & 0,8095 & Sangat Tinggi \\
\hline 11 & $\begin{array}{l}\text { Pengawasan Logistik Yang Lemah Sehingga Terjadi Hilangnya } \\
\text { Bahan Material }\end{array}$ & 0,8095 & Sangat Tinggi \\
\hline 12 & $\begin{array}{l}\text { Terjadinya Manipulasi Pada Logistik Proyek (Bekerja Sama } \\
\text { Dengan Supplier Material) Sehingga Jumlah Pengiriman Material } \\
\text { Berlebihan Atau Kekurangan }\end{array}$ & 0,8047 & Sangat Tinggi \\
\hline 13 & $\begin{array}{l}\text { Terlambat Atau Kurangnya Pasokan Material Pada Saat } \\
\text { Pelaksanaan }\end{array}$ & 0,8047 & Sangat Tinggi \\
\hline 14 & $\begin{array}{l}\text { Koordinasi Yang Kurang Baik Antara Site Manager dan Pekerja } \\
\text { Proyek Di Lapangan }\end{array}$ & 0,8000 & Sangat Tinggi \\
\hline 15 & Sering Terjadi Penundaan Pekerjaan & 0,7952 & Tinggi \\
\hline 16 & Penjadwalan Proyek Yang Tidak Tepat Sasaran & 0,7857 & Tinggi \\
\hline 17 & Kontrol dan Pengendalian Kualitas Material Yang Buruk & 0,7809 & Tinggi \\
\hline 18 & $\begin{array}{l}\text { Harga Sewa Atau Beli Peralatan Yang Tinggi Akibat Tidak } \\
\text { Dilakukan Survei Terlebih Dahulu }\end{array}$ & 0,7761 & Tinggi \\
\hline 19 & $\begin{array}{l}\text { Biaya Mobilisasi Atau Demobilisasi Peralatan Yang Tinggi Akibat } \\
\text { Tidak Cermat Dalam Pengamatan di Lokasi Proyek }\end{array}$ & 0,7666 & Tinggi \\
\hline 20 & $\begin{array}{l}\text { Perencanaan Durasi Kontrak Jangka Pendek Yang Terlalu } \\
\text { Dipaksakan }\end{array}$ & 0,7619 & Tinggi \\
\hline 21 & Tidak Adanya Penjadwalan Dalam Pengadaan Material & 0,7571 & Tinggi \\
\hline 22 & Terlambatnya Proses Pembayaran Dari Owner & 0,7476 & Tinggi \\
\hline 23 & Dokumen Kontrak Yang Kurang Lengkap & 0,7380 & Tinggi \\
\hline 24 & Buruknya Kondisi Cuaca & 0,7238 & Tinggi \\
\hline 25 & $\begin{array}{l}\text { Tidak Memperhitungkan Inflasi Ekonomi Nasional dan Eskalasi } \\
\text { Kenaikan Harga Material }\end{array}$ & 0,6761 & Tinggi \\
\hline 26 & Besarnya Upah atau Gaji Sumber Daya Manusia & 0,6571 & Tinggi \\
\hline 27 & Adanya Kerusakan Terhadap Peralatan Yang Digunakan & 0,6428 & Tinggi \\
\hline
\end{tabular}




\section{Pembahasan}

Pada penelitian ini, teridentifikasi terdapat 7 kategori dengan 27 variabel yang menjadi penyebab terjadinya cost overrun (pembengkakan biaya) pada proyek rumah tinggal. Variabel yang menjadi pertanyaan dalam kuesioner diuji terlebih dahulu dengan uji validitas untuk mengetahui valid atau tidaknya variabel yang digunakan. Dari hasil uji validitas yang telah dilakukan, 27 variabel tersebut valid untuk digunakan sebagai variabel uji. Kemudian, dilakukan uji reliabilitas terhadap 7 kategori tersebut. 7 kategori tersebut lolos uji reliabilitas dengan nilai $>0$,6. Dari setiap variabel tersebut, dilakukan uji relative importance index (RII) untuk menentukan tingkat kepentingan dari setiap variabel terhadap topik yang dibahas. Dari hasil uji relative importance index (RII), menunjukkan bahwa terdapat 14 variabel dengan kategori tingkat kepentingan sangat tinggi $(\geq 0,8)$. 14 variabel tersebut menjadi faktor utama penyebab cost overrun berdasarkan respon para responden karena memiliki tingkat kepentingan sangat tinggi dalam pengaruhnya terhadap cost overrun (pembengkakan biaya) pada proyek rumah tinggal.

\section{KESIMPULAN DAN SARAN}

\section{Kesimpulan}

Berdasarkan penelitian yang telah dilakukan, faktor-faktor utama penyebab terjadinya cost overrun (pembengkakan biaya) pada proyek rumah tinggal adalah, sebagai berikut:

1. Data dan informasi proyek kurang lengkap (saat aanwijzing).

2. Perencanaan estimasi biaya material dan upah yang keliru.

3. Kekeliruan dan kesalahan dalam pengontrolan biaya proyek.

Faktor-faktor diatas menjadi faktor dengan kategori tingkat kepentingan sangat tinggi berdasarkan uji dengan metode relative importance index (RII) dengan nilai $\geq 0,85$. Dari uji RII tersebut, variabel-variabel diatas teridentifikasi menjadi faktor utama penyebab terjadinya cost overrun pada proyek rumah tinggal. Terdapat 11 variabel lain dengan tingkat kepentingan kategori sangat tinggi dengan nilai < 0,85. 13 variabel terakhir memilki tingkat kepentingan dengan kategori tinggi dalam pengaruhnya terhadap cost overrun pada proyek rumah tinggal.

\section{Saran}

Dari penelitian yang telah dilakukan, beberapa saran dalam menghadapi masalah cost overrun pada suatu proyek diantaranya:

1. Pihak owner dan konsultan perencana perlu memperhatikan kembali terkait informasi mengenai kontrak, rencana kerja dan syarat, dan gambar design supaya hal tersebut tidak menimbulkan kekeliruan oleh penyedia jasa konstruksi. Apabila terdapat perubahan, sebaiknya didiskusikan kembali dengan penyedia jasa konstruksi untuk mencegah cost overrun selama berjalannya proyek.

2. Diperlukan adanya kolaborasi antara konsultan perencana dan penyedia jasa konstruksi apabila terjadi perubahan harga satuan dan pengaturan upah pekerja lapangan dalam merencanakan rancangan anggaran biaya terkait biaya material dan upah.

3. Konsultan perencana dan owner perlu memperhatikan kembali rancangan anggaran biaya yang dibuat serta jenis pembayaran yang dilakukan kepada penyedia jasa konstruksi untuk mencegah pengeluaran anggaran biaya yang berlebih serta dapat mengontrol biaya proyek.

\section{DAFTAR PUSTAKA}

Departemen Pekerjaan Umum. (2007). Pelatihan Ahli Manajemen Konstruksi (Ahli Muda) (Construction Management). Jakarta: BADAN PEMBINAAN KONSTRUKSI DAN SUMBER DAYA MANUSIA PUSAT PEMBINAAN KOMPETENSI DAN PELATIHAN KONSTRUKSI.

Flyvbjerg, B., Ansar, A., Ansar, A., Buhl, S., Cantarelli, C., Garbuio, M., . . . Wee, B. v. (2018). Five things you should know about cost overrun. Transportation Research Part A, 174-190.

Love, P. E., Wang, X., Sing, C.-p., \& Tiong, R. L. (2013). Determining the Probability of Project Cost Overruns. Journal of Construction Engineering and Management, 321-330.

PMBOK Guide. (2013). A Guide to the Project Management Body of Knowledge. Pennsylvania: Project Management Institute, Inc.

Ritz, G. J. (1994). Total Construction Project Management. Boston: McGraw-Hill.

Tolangi, M. F., Rantung, J., Langi, J., \& Sibi, M. (2012). Analisis Cash Flow Optimal Pada Kontraktor Proyek Pembangunan Perumahan. Jurnal Sipil Statik, 60-64. 